\title{
Association of apolipoprotein A1 -75 G/A polymorphism with susceptibility to the development of acute lung injury after cardiopulmonary bypass surgery
}

Jie Tu, Bingdong Zhang ${ }^{*}$, Yanhua Chen, Beiwei Liang, Dongke Liang, Guofeng Liu and Fang He

\begin{abstract}
Introduction: Apolipoprotein A1 (apoA1) is the major apoprotein constituent of high density lipoprotein (HDL) which exerts innate protective effects in systemic inflammation. However, its role in the acute lung injury (ALI) or acute respiratory distress syndrome (ARDS) has not been well studied. The objective of this study was to investigate the potential association between APOA1 -75 G/A polymorphism and the development of ALI after cardiopulmonary bypass (CPB) surgery.

Materials and methods: A hospital-based case-control study was conducted in patients with ALI ( $\mathrm{n}=300)$, patients without ALI $(n=300)$ and healthy controls $(n=300)$. Polymerase chain reaction restriction fragment length polymorphism (PCR-RFLP) assay was applied to assess the APOA1 -75 G/A genotypes.

Results: Patients with ALI had a significantly higher frequency of APOA1 -75 AA genotype [odds ratio (OR) $=1.75,95 \%$ confidence interval $(\mathrm{Cl})=1.04,2.92 ; P=0.03$ ] than patients without ALI. APOA1 -75 AA genotype $(\mathrm{OR}=3.47$, $95 \% \mathrm{Cl}=1.60,7.52 ; P=0.002)$ and $\mathrm{A}$ allele $(\mathrm{OR}=1.92,95 \% \mathrm{Cl}=1.24,2.96 ; P=0.003)$ were the significant independent prognostic factors for the 30-day survival rate of patients with ALI after CPB surgery.

Conclusion: Our study suggested that APOA1 -75 AA genotype was associated with a higher ALI risk after CPB surgery. Patients with the APOA1 -75 AA genotype and A allele had higher 30-day mortality of ALI after CPB surgery. Additional studies are needed to confirm this finding.
\end{abstract}

Keywords: Apolipoprotein A1, Acute lung injury, Cardiopulmonary bypass, Gene polymorphism

\section{Introduction}

Acute lung injury (ALI) is a common complication after cardiopulmonary bypass (CPB) surgery. ALI remains the main cause of mortality after CPB surgery [1]. The main causes of ALI after CPB surgery have been identified, including ischemia reperfusion injury, endotoxemia, primary pulmonary disease, surgical injury, and the systemic inflammatory reaction initiated by the contact of the blood leukocytes with the artificial surface of the bypass circuit [2-5]. Improved understanding of disease heterogeneity through use of evolving biologic, genomic, and genetic

\footnotetext{
* Correspondence: bingdongzhang@live.cn

Institute of cardiovascular Diseases, The First Affiliated Hospital of Guangxi, Medical University, 6 ShuangYong Road, Nanning, Guangxi 530021, China
}

approaches should provide major new insights into pathogenesis of ALI [6].

Apolipoprotein A1 (apoA1) is the major apoprotein constituent of high density lipoprotein (HDL) which exerts innate protective effects in systemic inflammation [7]. However, its role in the acute lung injury (ALI) or acute respiratory distress syndrome (ARDS) has not been well studied. One variant resides in the APOA1 gene, which involves a guanine to adenine transition 75 base pairs (bp) upstream from the start of transcription $(\mathrm{G}-75 \mathrm{~A})$ and destroys a site for the $M s p \mathrm{I}$ restriction enzyme. A strong association was found between the $G$ to A substitution at -75 bp with serum HDL and apoA1 levels [8]. The objective of this study was to investigate the potential association between APOA1-75 G/A polymorphism and the 
development of ALI after cardiopulmonary bypass (CPB) surgery.

\section{Materials and methods Study population}

From January 2008 to January 2013, a hospital-based case-control study was conducted in patients with ALI $(\mathrm{n}=300)$, patients without ALI $(\mathrm{n}=300)$ after CPB surgery and healthy controls $(\mathrm{n}=300)$ in the Institute of cardiovascular Diseases of the First Affiliated Hospital of Guangxi Medical University. All subjects were collected from the same geographic region. Surgery type included valvular surgery, coronary artery bypass graft (CABG) and aortic surgery. The healthy control subjects were matched with the patients for age and sex. Healthy control subjects were recruited from the First Affiliated Hospital of Guangxi Medical University where they were attending a clinic for routine examination. Patients who met diagnostic criteria of acute lung injury at 24 hours after surgery were allocated to ALI group; those without ALI were allocated to without ALI group. ALI was defined as $\mathrm{PaO}_{2} / \mathrm{FiO}_{2}<300 \mathrm{~mm} \mathrm{Hg}$; and bilateral pulmonary infiltrates on chest radiograph in the absence of acute pulmonary edema after left cardiac failure or other nonlung pathology 24 hours after surgery, and a left atrial pressure lower than $18 \mathrm{~mm} \mathrm{Hg}$ [9]. Patients were excluded if they met the following criteria: immunodeficiency, autoimmune disease, or immunosuppressive therapy; tuberculosis, chronic obstructive pulmonary disease (COPD), or other chronic pulmonary diseases; liver dysfunction or chronic renal disease; bleeding disorders; anemia; postoperative pericardial tamponade requiring reoperation; postoperative low cardiac output syndrome, or acute pulmonary edema after left cardiac failure. The Ethical Committee of the First Affiliated Hospital of Guangxi Medical University approved the study protocols, and all participants gave written informed consent according to the Declaration of Helsinki.

\section{DNA extraction and genotyping}

The commercially available Qiagen kit (QIAGEN Inc., Valencia, CA, USA) was used to extract DNA from peripheral blood leukocytes. The APOA1 -75 G/A genotypes were analyzed by polymerase chain reaction-restriction fragment length polymorphism (PCR-RFLP) assay. Based on the GenBank reference sequence, the PCR primers were as follows: forward-5' - AGGGACAGAGCTGAT CC-TTGAACTCTTAG $-3^{\prime}$ and reverse-5' - TTAGGG GACACCTACCCGTACAGGAAGAGCA - $3^{\prime}$. DNA was denaturanted at $94^{\circ} \mathrm{C}$ for 5 minutes, followed by 35 cycles of denaturation at $94^{\circ} \mathrm{C}$ for 1 minute, annealing at $60^{\circ} \mathrm{C}$ for 0.5 minute, and extension at $72^{\circ} \mathrm{C}$ for 0.5 minutes, with a final extension step of 5 minutes at $72^{\circ} \mathrm{C}$. A total volume of $10 \mu \mathrm{l}$ containing $20 \mathrm{U}$ MspI was added directly to the PCR product and digested at $37^{\circ} \mathrm{C}$ overnight. After electrophoresis, the digested products were visualized on a $9 \%$ polyacrylamide gel with ethidium bromide staining.

\section{Statistical analysis}

We used Statistical Analysis System software (Version 8; SAS Institute Inc., Cary, NC, USA) to perform all of the statistical analyses. The $x^{2}$ test was used to test for deviation of genotype frequencies from Hardy-Weinberg equilibrium and to compare the genotype distributions among patients with ALI, patients without ALI and healthy controls. We applied multivariate logistic regression to calculate crude and adjusted odds ratios (OR) and 95\% confidence intervals $(\mathrm{CI})$ for the association between the genotypes and the development of ALI after CPB surgery. A $P$-value was considered significant at a level of $<0.05$.

\section{Results}

Clinical data of patients with or without ALI after CPB surgery were listed in Table 1 . Univariate study was performed to identify that age $(P=0.005)$, NYHA $(P=0.02)$, obesity $(P=0.03)$, peripheral vascular disease $(P=0.03)$, duration of operation $(P=0.003)$, and duration of $\mathrm{CPB}$ $(P=0.04)$ were associated with ALI after CPB surgery (Table 1). In addition, no significant differences were

Table 1 Clinical data of patients with or without ALI after CPB surgery

\begin{tabular}{lccl}
\hline Variable & ALI & Without ALI & $P$ \\
\hline Total no. & 300 & 300 & \\
Age (years) & $59.1 \pm 10.6$ & $56.8 \pm 9.4$ & 0.005 \\
Gender (Male/Female) & $205 / 95$ & $201 / 99$ & 0.73 \\
ASA & $2.77 \pm 0.71$ & $2.67 \pm 0.65$ & 0.07 \\
NYHA & $2.69 \pm 0.67$ & $2.57 \pm 0.55$ & 0.02 \\
LVEF (\%) & $59.68 \pm 7.94$ & $60.68 \pm 8.04$ & 0.13 \\
Previous cardiac surgery (\%) & $45(15.0)$ & $30(10.0)$ & 0.07 \\
Hypertension (\%) & $75(25.0)$ & $70(23.3)$ & 0.63 \\
Diabetes mellitus (\%) & $26(8.7)$ & $24(8.0)$ & 0.77 \\
Obesity (\%) & $70(23.3)$ & $48(16.0)$ & 0.03 \\
Peripheral vascular disease (\%) & $43(14.3)$ & $26(8.7)$ & 0.03 \\
Transfusion (mL) & $694.3 \pm 103.7$ & $687.3 \pm 99.8$ & 0.40 \\
Duration of operation (min) & $231.7 \pm 90.1$ & $210.5 \pm 82.3$ & 0.003 \\
Duration of CPB (min) & $106.7 \pm 43.7$ & $99.5 \pm 41.5$ & 0.04 \\
Duration of cross-clamp (min) & $62.1 \pm 32.4$ & $60.7 \pm 31.9$ & 0.59 \\
Surgery & & & \\
$\quad$ Valvular surgery (\%) & $176(58.7)$ & $183(61.0)$ & 0.56 \\
$\quad$ CABG surgery (\%) & $99(33.0)$ & $102(34.0)$ & 0.80 \\
$\quad$ Aortic surgery (\%) & $25(8.3)$ & $15(5.0)$ & 0.11 \\
\hline ALI, Acute Ing in & & & \\
\hline
\end{tabular}

$A L I$, Acute lung injury; $C P B$, Cardiopulmonary bypass; $A S A$, American Society of Anesthesiology; NYHA, New York Heart Association; LVEF, Left ventricular ejection fraction; $C A B G$, Coronary artery bypass graft. 
found between the patients with or without ALI after CPB surgery in gender, ASA, LVEF, previous cardiac surgery, hypertension, diabetes mellitus, transfusion, duration of cross-clamp, and surgery type (Table 1 ).

Patients with ALI had a significantly higher frequency of $A P O A 1-75$ AA genotype $(\mathrm{OR}=1.75,95 \% \mathrm{CI}=1.04$, 2.92; $P=0.03$ ) than patients without ALI (Table 2). APOA1 -75 AA genotype $(\mathrm{OR}=3.47,95 \% \mathrm{CI}=1.60$, 7.52; $P=0.002)$ and A allele $(\mathrm{OR}=1.92,95 \% \mathrm{CI}=1.24$, 2.96; $P=0.003$ ) were the significant independent prognostic factors for the 30-day survival rate of patients with ALI after CPB surgery (Table 3).

\section{Discussion}

Some studies have been performed to find an association of genetic polymorphism and ALI [10]. A prospective case-control study found that $-607 \mathrm{C} / \mathrm{C}$ genotype in IL18 gene played a pivotal role in the development of ALI after CPB surgery in Chinese Han population [11]. Another case-control study found that the IL-6 -572 polymorphism was associated with ALI after CPB surgery [12]. Several studies have suggested that pre-B-cell colonyenhancing factor (PBEF) gene polymorphisms were associated with susceptibility to and prognosis of ALI $[13,14]$. The plasminogen activator inhibitor-1 (PAI-1) 4G allele was associated with worse outcome in ALI/ARDS [15]. A prospective cohort demonstrated that the AC genotype at position -1221 in the NQO1 gene caused decreased transcription and was associated with a lower incidence of ALI following major trauma [16]. In a nested case-control study, patients with the NRF2 -617 A allele had a significantly higher risk for developing ALI after major trauma [17]. A case-control study found that myosin light chain kinase (MYLK) genetic variants were associated with increased risk of sepsis-associated ALI [18].

The APOA1 -75 G/A polymorphism has recently been linked to many other diseases. A comparative study found that carrying the APOA1 -75 A allele could confer a higher risk of hyperlipidemia in obese children
Table 3 Effect of apolipoprotein A1 -75 G/A polymorphism on the 30-day survival rate of patients with ALI after CPB surgery

\begin{tabular}{ccccc}
\hline & $\begin{array}{c}\text { Non-survivors } \\
(\mathbf{n}=\mathbf{5 0})\end{array}$ & $\begin{array}{c}\text { Survivors } \\
(\mathbf{n}=\mathbf{2 5 0})\end{array}$ & OR $(\mathbf{9 5 \%} \mathbf{C I})$ & $\boldsymbol{P}$ value \\
\hline Genotype & & & & \\
GG & $18(36.0)$ & $114(45.6)$ & 1.00 (Reference) & \\
GA & $15(30.0)$ & $105(42.0)$ & $0.91(0.43,1.89)$ & 0.79 \\
AA & $17(34.0)$ & $31(12.4)$ & $3.47(1.60,7.52)$ & 0.002 \\
Allele & & & & \\
G & $51(51.0)$ & $333(66.6)$ & 1.00 (Reference) & \\
A & $49(49.0)$ & $167(33.4)$ & $1.92(1.24,2.96)$ & 0.003 \\
\hline
\end{tabular}

$A L I$, Acute lung injury; $C P B$, Cardiopulmonary bypass; $O R$, Odds ratio; $\mathrm{Cl}$, Confidence interval.

[19]. A prospective case-control study found that the APOA1 -75 G/A polymorphism influenced cholesterol metabolism [20]. A study in healthy Tamilian volunteers of south India found that the APOA1 -75 G/A polymorphism was significantly associated with HDL-C levels [21]. A study found the APOA1 -75 G/A polymorphism was significantly associated with plasma triglyceride levels in men with coronary artery disease from the REGRESS study [22]. A case-control study found the APOA1 -75G/ A promoter polymorphism was associated with variations in serum triglyceride concentrations in hypercholesterolemic individuals [23]. A case-control study suggested that a positive association was found between the APOA1 -75 A allele carriers and breast cancer risk [24]. A pilot study in a north Indian population suggested that the APOA1 -75 $\mathrm{G}$ allele might be susceptibility alleles for myocardial infarction [25]. A case-control study found an association of the APOA1 -75G/A promoter polymorphism with cognitive performance in multiple sclerosis [26]. A cohort study found that the APOA1 -75 G allele showed significant association with hypertension [27]. A casecontrol study found the APOA1 -75 G/A polymorphism was associated with gallstone disease [28]. A case-control

Table 2 Genotype and allele frequencies of apolipoprotein A1 -75 G/A polymorphism among patients with or without ALI after CPB surgery and controls

\begin{tabular}{|c|c|c|c|c|c|c|c|c|c|}
\hline & \multirow{2}{*}{$\begin{array}{c}\text { ALI } \\
(n=300)\end{array}$} & \multirow{2}{*}{$\begin{array}{l}\text { Without ALI } \\
(n=300)\end{array}$} & \multirow{2}{*}{$\begin{array}{l}\text { Healthy controls } \\
\quad(\mathrm{n}=300)\end{array}$} & \multicolumn{2}{|c|}{$A L I$ vs without $A L I$} & \multicolumn{2}{|c|}{ ALI vs healthy controls } & \multicolumn{2}{|c|}{ Without ALI vs healthy controls } \\
\hline & & & & OR $(95 \% \mathrm{Cl})$ & $P$ value & OR $(95 \% \mathrm{Cl})$ & $P$ value & OR $(95 \% \mathrm{Cl})$ & $P$ value \\
\hline \multicolumn{10}{|c|}{ Genotype } \\
\hline GG & $132(44.0)$ & 144(48.0) & 138(46.0) & 1.00(Reference) & & 1.00(Reference) & & 1.00(Reference) & \\
\hline GA & $120(40.0)$ & $126(42.0)$ & 129(43.0) & $1.04(0.74,1.47)$ & 0.83 & $0.97(0.69,1.37)$ & 0.87 & $0.94(0.67,1.31)$ & 0.70 \\
\hline AA & $48(16.0)$ & $30(10.0)$ & $33(11.0)$ & $1.75(1.04,2.92)$ & 0.03 & $1.52(0.92,2.52)$ & 0.10 & $0.87(0.50,1.51)$ & 0.62 \\
\hline \multicolumn{10}{|c|}{ Allele } \\
\hline G & $384(64.0)$ & $414(69.0)$ & $405(67.5)$ & 1.00(Reference) & & 1.00(Reference) & & 1.00(Reference) & \\
\hline A & $216(36.0)$ & 186(31.0) & 195(32.5) & $1.25(0.99,1.59)$ & 0.07 & $1.17(0.92,1.48)$ & 0.20 & $0.93(0.73,1.19)$ & 0.58 \\
\hline
\end{tabular}

$A L I$, Acute lung injury; $C P B$, Cardiopulmonary bypass; vs, versus; $O R$, Odds ratio; $C l$, Confidence interval. 
study found the APOA1 -75 A allele was associated with an increased risk for Alzheimer's disease [29]. A casecontrol study found the APOA1 -75 G/A polymorphism was significantly associated with lipid levels and coronary atherosclerosis disease [30].

Some limitations of this study should be noted. First of all, these results should be interpreted with caution because the population was only from China, which reduces the possibility of confounding from ethnicity, so it does not permit extrapolation of the results to other ethnic groups. Second, the sample size of this study is relatively small, which may not have enough statistical power to explore the real association. Third, this is a hospital based case control study, so the selection bias cannot be avoidable and the subjects may not be representative of the general population.

In conclusion, our study suggested that APOA1 -75 AA genotype was associated with a higher ALI risk after CPB surgery. Patients with the APOA1 -75 AA genotype and A allele had higher 30-day mortality of ALI after $\mathrm{CPB}$ surgery. Additional studies are needed to confirm this finding.

\section{Competing interest}

The authors declare that they have no competing interests.

\section{Authors' contributions}

JT and BZ carried out the molecular genetic studies and drafted the manuscript. YC and BL carried out the genotyping. DL, GL participated in the design of the study and performed the statistical analysis. FH conceived of the study, and participated in its design and coordination and helped to draft the manuscript. All authors read and approved the final manuscript.

\section{Acknowledgement}

This research received no specific grant from any funding agency in the public, commercial, or not-for-profit sectors.

Received: 17 October 2013 Accepted: 28 October 2013

Published: 11 November 2013

\section{References}

1. Hammermeister KE, Burchfiel C, Johnson R, Grover FL: Identification of patients at greatest risk for developing major complications at cardiac surgery. Circulation 1990, 82:IV380-IV389.

2. Wakayama F, Fukuda I, Suzuki Y, Kondo N: Neutrophil elastase inhibitor, sivelestat, attenuates acute lung injury after cardiopulmonary bypass in the rabbit endotoxemia model. Ann Thorac Surg 2007, 83:153-160.

3. Westaby S, Fleming J, Royston D: Acute lung injury during cardiopulmonary bypass, the role of neutrophil sequestration and lipid peroxidation. Trans Am Soc Artif Intern Organs 1985, 31:604-609.

4. Bando K, Pillai R, Cameron DE, Brawn JD, Winkelstein JA, Hutchins GM, Reitz BA, Baumgartner WA: Leukocyte depletion ameliorates free radical-mediated lung injury after cardiopulmonary bypass. J Thorac Cardiovasc Surg 1990, 99:873-877.

5. Asimakopoulos G, Smith PL, Ratnatunga CP, Taylor KM: Lung injury and acute respiratory distress syndrome after cardiopulmonary bypass. Ann Thorac Surg 1999, 68:1107-1115.

6. Matthay MA, Zimmerman GA, Esmon C, Bhattacharya J, Coller B, Doerschuk CM, Floros J, Gimbrone MA Jr, Hoffman E, Hubmayr RD, et al: Future research directions in acute lung injury: summary of a National Heart, Lung, and Blood Institute working group. Am J Respir Crit Care Med 2003, 167:1027-1035.

7. Albahrani Al, Usher JJ, Alkindi M, Marks E, Ranganath L, Al-yahyaee S: ApolipoproteinA1-75 G/A (M1-) polymorphism and lipoprotein(a); anti- vs. pro-Atherogenic properties. Lipids Health Dis 2007, 6:19.
8. Saha N, Tay JS, Low PS, Humphries SE: Guanidine to adenine (G/A) substitution in the promoter region of the apolipoprotein $\mathrm{Al}$ gene is associated with elevated serum apolipoprotein Al levels in Chinese non-smokers. Genet Epidemiol 1994, 11:255-264.

9. Bernard GR, Artigas A, Brigham KL, Carlet J, Falke K, Hudson L, Lamy M, Legall JR, Morris A, Spragg R: The American-European Consensus Conference on ARDS. Definitions, mechanisms, relevant outcomes, and clinical trial coordination. Am J Respir Crit Care Med 1994, 149:818-824.

10. Reddy AJ, Kleeberger SR: Genetic polymorphisms associated with acute lung injury. Pharmacogenomics 2009, 10:1527-1539.

11. Chen S, Xu L, Tang J: Association of interleukin 18 gene polymorphism with susceptibility to the development of acute lung injury after cardiopulmonary bypass surgery. Tissue Antigens 2010, 76:245-249.

12. Wang JF, Bian JJ, Wan XJ, Zhu KM, Sun ZZ, Lu AD: Association between inflammatory genetic polymorphism and acute lung injury after cardiac surgery with cardiopulmonary bypass. Med Sci Monit 2010, 16:CR260-CR265.

13. Liu Y, Shao Y, Yu B, Sun L, Lv F: Association of PBEF gene polymorphisms with acute lung injury, sepsis, and pneumonia in a northeastern Chinese population. Clin Chem Lab Med 2012, 50:1917-1922.

14. Bajwa EK, Yu CL, Gong MN, Thompson BT, Christiani DC: Pre-B-cell colonyenhancing factor gene polymorphisms and risk of acute respiratory distress syndrome. Crit Care Med 2007, 35:1290-1295.

15. Tsangaris I, Tsantes A, Bonovas S, Lignos M, Kopterides P, Gialeraki A, Rapti E, Orfanos S, Dimopoulou I, Travlou A, Armaganidis A: The impact of the PAI-1 $4 \mathrm{G} / 5 \mathrm{G}$ polymorphism on the outcome of patients with ALI/ARDS. Thromb Res 2009, 123:832-836.

16. Reddy AJ, Christie JD, Aplenc R, Fuchs B, Lanken PN, Kleeberger SR: Association of human NAD(P)H: quinone oxidoreductase 1 (NQO1) polymorphism with development of acute lung injury. I Cell Mol Med 2009, 13:1784-1791.

17. Marzec JM, Christie JD, Reddy SP, Jedlicka AE, Vuong H, Lanken PN, Aplenc R, Yamamoto T, Yamamoto M, Cho HY, Kleeberger SR: Functional polymorphisms in the transcription factor NRF2 in humans increase the risk of acute lung injury. FASEB J 2007, 21:2237-2246.

18. Gao L, Grant A, Halder I, Brower R, Sevransky J, Maloney JP, Moss M, Shanholtz C, Yates CR, Meduri GU, et al: Novel polymorphisms in the myosin light chain kinase gene confer risk for acute lung injury. Am J Respir Cell Mol Biol 2006, 34:487-495.

19. Toptas B, Gormus U, Ergen A, Gurkan H, Kelesoglu F, Darendeliler F, Bas F, Dalan AB, Izbirak G, Isbir T: Comparison of lipid profiles with APOA1 Mspl polymorphism in obese children with hyperlipidemia. In Vivo 2011, 25:425-430.

20. Smach MA, Edziri H, Charfeddine B, Ben Othman L, Lammouchi T, Ltaief A, Nafati S, Dridi H, Bennamou S, Limem K: Polymorphism in apoA1 influences high-density lipoprotein cholesterol levels but is not a major risk factor of alzheimer's disease. Dement Geriatr Cogn Dis Extra 2011, 1:249-257.

21. Padmaja N, Kumar MR, Adithan C: Association of polymorphisms in apolipoprotein A1 and apolipoprotein B genes with lipid profile in Tamilian population. Indian Heart J 2009, 61:51-54.

22. Souverein OW, Jukema JW, Boekholdt SM, Zwinderman AH, Tanck MW: Polymorphisms in APOA1 and LPL genes are statistically independently associated with fasting TG in men with CAD. Eur J Hum Genet 2005, 13:445-451.

23. Sorkin SC, Forestiero FJ, Hirata MH, Guzman EC, Cavalli SA, Bertolami MC, Salazar LA, Hirata RD: APOA1 polymorphisms are associated with variations in serum triglyceride concentrations in hypercholesterolemic individuals. Clin Chem Lab Med 2005, 43:1339-1345.

24. Hamrita B, Ben Nasr H, Gabbouj S, Bouaouina N, Chouchane L, Chahed K: Apolipoprotein A1-75 G/A and $+83 \mathrm{C} / \mathrm{T}$ polymorphisms: susceptibility and prognostic implications in breast cancer. Mol Biol Rep 2011, 38:1637-1643

25. Dawar R, Gurtoo A, Singh R: Apolipoprotein A1 gene polymorphism (G-75A and $C+83 \mathrm{~T}$ ) in patients with myocardial infarction: a pilot study in a north Indian population. Am J Clin Pathol 2010, 134:249-255.

26. Koutsis G, Panas M, Giogkaraki E, Karadima G, Sfagos C, Vassilopoulos D: An APOA1 promoter polymorphism is associated with cognitive performance in patients with multiple sclerosis. Mult Scler 2009, 15:174-179.

27. Chen ES, Mazzotti DR, Furuya TK, Cendoroglo MS, Ramos LR, Araujo LQ, Burbano RR, de Arruda Cardoso Smith M: Apolipoprotein A1 gene 
polymorphisms as risk factors for hypertension and obesity. Clin Exp Med 2009, 9:319-325

28. Dixit M, Choudhuri G, Saxena R, Mittal B: Association of apolipoprotein A1-C3 gene cluster polymorphisms with gallstone disease. Can J Gastroenterol 2007, 21:569-575.

29. Vollbach H, Heun R, Morris CM, Edwardson JA, McKeith IG, Jessen F, Schulz A, Maier W, Kolsch H: APOA1 polymorphism influences risk for early-onset nonfamiliar AD. Ann Neurol 2005, 58:436-441.

30. Zou Y, Hu D, Yang X, Jia X, Wang L, Cui L, Liu X, Gao M, Wei Y, Xu Z: Relationships among apolipoprotein A1 gene polymorphisms, lipid levels and coronary atherosclerosis disease. Chin Med J (Engl) 2003, 116:665-668.

doi:10.1186/1476-511X-12-172

Cite this article as: Tu et al:: Association of apolipoprotein A1 -75 G/A polymorphism with susceptibility to the development of acute lung injury after cardiopulmonary bypass surgery. Lipids in Health and Disease 2013 12:172.

\section{Submit your next manuscript to BioMed Central and take full advantage of:}

- Convenient online submission

- Thorough peer review

- No space constraints or color figure charges

- Immediate publication on acceptance

- Inclusion in PubMed, CAS, Scopus and Google Scholar

- Research which is freely available for redistribution 